\title{
Trust attributes of mobile applications for improved self-management of diabetes in South Africa
}

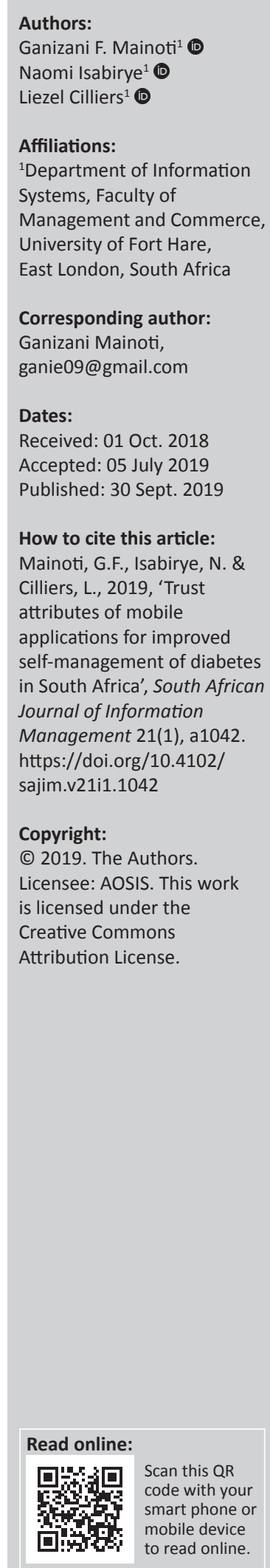

Background: Information technology (IT) trust is an important concept as people today rely more on IT to perform their tasks than before. A current review of information systems literature suggests that trust in technology is a key determinant of technology adoption, use and an accelerator of understanding user perception. User perceptions of a technology's characteristics influences the users' initial decision to adopt the technology, while the user is less likely to make use of the technology if they perceive significant risk linked to the technology exploration.

Objectives: This study focused on trust in relation to adoption of mobile applications for selfmanagement of diabetic treatment regimens. The aim was to identify components that should be incorporated into these applications to positively influence user perception of trustworthiness for enhanced adoption.

Method: This research study adopted the qualitative research approach with a survey design. Questionnaires were used to solicit user trust opinions and views of mobile applications for diabetes treatment management influencing adoption and continued use. Twenty people living with diabetes participated in the study by agreeing to download and try the Diabetes:M application, a diabetes self-management application for mobile devices from Google Play store. The diabetes application enables patients to log their treatment, create reminders and track treatment progress.

Results: Functionality, usability, information accuracy and reliable information generated by diabetes applications were important elements identified by patients to trust these applications.

Conclusion: Research findings showed that the applications for diabetes self-management should be usable, possess enough functionalities, give accurate information for decisionmaking, be reliable and secure to enhance the trust of people with diabetes.

Keywords: Trust; adoption; self-management; diabetes; mobile applications.

\section{Introduction}

Mobile health applications refer to software tools that can assist users to monitor their health conditions through smartphones and tablets. Their functionality ranges from allowing users to maintain simple diaries, create medication reminders, track health progress to more complex programmes certified by health authorities as medical devices (Wicks \& Chiauzzi 2015). Currently, the potential of mobile health applications to improve healthcare is very good, with at least half a million users making use of them. However, scholars such as Schnall et al. (2015) found that the trustworthiness of these applications is still questionable, limiting large-scale user adoption. To date, extensive research about trust in technology and the role of user trust in the selection of different information technology (IT) artefacts have not been explored. Nyoni and Piderit (2012) and Huang and Nicol (2013) explored the impact of trust in cloud computing platforms; Isabirye et al. (2015) investigated trust in rural agricultural e-marketplaces. Schnall et al. (2015) examined trust in mobile applications for people living with human immunodeficiency virus (HIV) and acquired immune deficiency syndrome (AIDS).

Trust is characterised as the certainty that the conduct of one party will fit in with another's desires and inside the goodwill of the other person (Hart \& Saunders 1997). This meaning of trust, nevertheless, applies to interpersonal relationships. Soderstrom (2009) suggests that trust can be classified in view of the diverse actors required in a trust relationship. According to this author, the classifications are interpersonal trust, administrative trust and mechanical trust. This research concentrated on mobile applications for self-management of diabetes treatment regimens. Accordingly, it falls under trust in technology, specifically focusing on the trust that people have 
in technological artefacts. In this study, the meaning of trust in technology, according to Koo and Wati (2010), is adopted. These authors define trust in the degree to which people depend on and are vulnerable to the technology after having considered the embedded characteristics of the technology. This study investigated components of trust in mobile applications for self-management for diabetes treatment regimes.

\section{Background and research problem}

Globally, diabetes is viewed as a significant cause of many deaths and disabilities (Brown \& Bussell 2011; Hamine et al. 2015). Presently, it is estimated that no less than 366 million individuals worldwide have diabetes, either type 1 or type 2 (Årsand et al. 2012). Furthermore, Årsand et al. (2012) described diabetes as a metabolic sickness that results in people having larger amounts of blood glucose than is normal as their bodies deliver inadequate insulin (type 1 diabetes) or their bodies do not react to the insulin that they create (type 2 diabetes). It was indicated by Dube et al. (2015) that the high burden of diabetes cases is profoundly felt in developing nations, where resources are limited, and the health delivery framework needs to manage both communicable and non-communicable disease cases simultaneously. In 2015, the International Diabetes Federation reported that around 3 million individuals were living with diabetes in South Africa.

Diabetes, like other chronic illnesses, requires a longlasting treatment arrangement. It is vital that people living with diabetes adhere to lifelong treatment plans to realise improved health and a good quality of life. Cost-effective healthcare for patients is also a national priority (Hamine et al. 2015). It was found by Goyal and Cafazzo (2013) that a lack of self-management skills by patients, unavailability of personalised education and clinical inertia have led to serious complications, exhaustive resource usage and very low quality of life for people living with diabetes. For a long time, people living with diabetes could deal with their illness by injecting themselves with insulin for a required number of 4-6 times each day to maintain their blood glucose levels to the required body and control levels (Khansa et al. 2016). However, while this strategy has been compelling and is still being utilised by patients today, the system depends on the patient's memory. In addition, Khansa et al. (2016) noted that in many instances patients overlooked whether they had received or not received their insulin injections on time. This brought about a shortage or an excess of insulin injected by patients per day. The ability of patients to keep their blood glucose at required levels is fundamental to minimising long-term diabetes complications (Nathan et al. 2005). Forgetting to inject insulin as and when required brings about a rise in a patient's blood glucose to unsafe levels, which can lead to serious health complications and additional financial expenditure related to insufficient self-management (Årsand et al. 2012; Goyal et al. 2015).
Prior studies found that incorporating IT into the delivery of medicinal services, including for patients with diabetes, could be compelling in enhancing their general well-being at a low cost (Jackson et al. 2006). As such, the rise of mobile health applications has extraordinarily reformed the potential for telephone-based interventions for people living with diabetes (Kumar et al. 2013). It is suggested by Schnall et al. (2015) that through using mobile applications to manage health, people living with diabetes have the potential to reduce serious implications and high rates of mortality because of better adherence to treatment regimens. Likewise, Dayer et al. (2013) found that mobile applications positively affect the treatment adherence behaviour among patients suffering from lifelong diseases such as asthma, diabetes and coronary illness. It was found by Perera et al. (2014) that mobile applications, unlike short messaging services (SMSs), additionally utilised as another mediation for patient follow-up on treatment adherence, could be customised to the individual patient, could incorporate multimedia information such as images and videos, and provide feedback in real time on a patient's adherence behaviour. For people living with diabetes conditions, mobile applications enable them to keep their blood glucose at required levels at all times to minimise long-term diabetes complications. This is achieved by allowing them to track their diet, receiving medication reminders, tracking their daily physical activity and tracking medication dosages.

However, while promising results from current writing are clear, there is still much to be learnt about how mobile applications can be used completely for self-management of diabetes (Goyal \& Cafazzo 2013). Goyal and Cafazzo (2013) state that, with the ease and accessibility of several applications for diabetes self-management for patients, it is challenging to identify those with clinical relevance. More importantly, the lack of trust in these applications has resulted in poor adoption by patients for selfmanagement of treatment regimens (Marcano et al. 2013). According to Jarvenpaa, Tractinsky and Vitale (2000), lack of trust is a result of perceived risk in health applications influenced by factors such as the distance between the patient and the healthcare provider. Patient trust in health applications is important as it is likely to influence behavioural intention to use the technology. However, despite the perceived view that mobile health applications can greatly support self-management behaviour among people living with diabetes, there exits concerns over the perceived trustworthiness of these platforms (Schnall et al. 2015). The research problem exists because people living with diabetes do not trust these applications to help them to adhere to their treatment regimens. Following on from the definition given earlier in this article for trust in technology, Mcknight et al. (2011) write that trust in a specific information system directly affects the readiness of clients to rely on it for the achievement of their objectives, in this case achieving medical objectives for people living with diabetes. 


\section{Methods}

The previous section provided the context and literature support for the study. This section explains the methodology used in the study to answer the research question.

\section{Design}

This research employed a survey research design to solicit user trust opinions and views of mobile applications for diabetes treatment management. Diabetes:M, a mobile health application for diabetes, which is available for download for free on Google Play store for Android devices and in the App Store for IOS devices were selected for review in the primary data collection phase. The mobile health application has functions that include allowing users to track glucose trends by enabling recording of test results, creating medication reminders and providing dietary information for patients living with diabetes. Besides the application having attracted the most positive reviews from users who have used or are still using the application, its selection was based on the rich features the application possesses compared to other applications reviewed. The application was recommended by the clinical staff members at the university healthcare centre based on the needs of diabetes patients on treatment. The selected application allows users to share health reports from the application with health specialists. Family members can also view and track health progress by login onto the online platform linked to the mobile application.

\section{Sample}

The study population comprised all adults living with diabetes in the East London area. A convenience sampling technique was used to identify the sample for this study. The final sample was composed of 20 adults who are people living with diabetes on chronic medication in East London. The selection of participants was based on specific criteria: the participants had to understand how to operate basic mobile applications such as calling, sending messages via SMS, social messaging applications such as WhatsApp and Facebook and own an Android smartphone device or IOS device to install the Diabetes: M app.

\section{Procedures}

The participants were asked to try the diabetes application for diabetes self-management on treatment adherence for at least 2 months. The link to the selected mobile application for diabetes treatment management was distributed to the participants via email. During this phase, the researcher followed up on participants to establish whether they had managed to access the application and install it on their devices. Three participants were supplied with mobile devices with the app already installed and ready for use. The rest were able to download and install the app on their devices. After successful installation, each participant was instructed to explore the application and use it for his or her day-to-day condition management over the research period.
After that, a questionnaire was sent to each participant for completion. However, not all participants responded on time as initially agreed. Others said they were too busy to complete the questionnaire and thought it was too long to complete. For those participants the principal researcher had to set up meetings to complete the questionnaire in the form of an interview. The questions were not changed and the data was recorded on the questionnaire by the researcher on behalf of the participants. The purpose of the data collection was to confirm the findings from the literature guided by the themes derived from the literature, which are explained briefly in Table 1.

\section{Data analysis}

Thematic analysis was used to analyse the collected data. Preselected themes (Table 1) derived from the literature review were used in the data analysis. Each questionnaire was studied, and recordings were made against each theme.

\section{Ethical consideration}

Ethical clearance was granted by the University of Fort Hare Research Ethics Committee (Certificate reference number: ISA031SMAI01).

\section{Findings}

In this section, the findings from the analysis are presented. The findings were organised according to the four broad themes: functionality, information accuracy, reliability and usability. These themes describe different aspects of the participants' trust opinions of mobile applications for diabetes treatment and adherence behaviour towards adoption and continued use of these applications. Each theme discussed the implication of the participants' experiences when using the diabetes application for the research period. Table 2 gives summaries of the findings.

\section{Discussion}

Similar to interpersonal trust, technology trust is generated by observing specific factors or characteristics of the trustee (Mcknight 2005). Findings from the literature reviewed and the results of the empirical analysis indicate that when people living with diabetes experience mobile applications, factors of functionality, usability (easy to learn and use),

TABLE 1: Trust themes derived from the literature.

\begin{tabular}{ll}
\hline Trust component & Explanation \\
\hline Functionality & $\begin{array}{l}\text { In IT artefacts, the functionality aspect is considered a significant } \\
\text { contributor towards influence on user trust (Lankton \& Mcknight } \\
\text { 2011). According to Mcknight et al. (2011), user expectations of } \\
\text { whether a technology has the capability to complete a required } \\
\text { task as required or not is an important contributory factor } \\
\text { towards influencing postadoption decisions of that IT. }\end{array}$ \\
$\begin{array}{ll}\text { Information accuracy affects the integrity dimension of trust-belief } \\
\text { accuracy }\end{array}$ & $\begin{array}{l}\text { in IT (Komiak 2010). } \\
\text { Reliability }\end{array}$ \\
$\begin{array}{l}\text { (Pyster et al. 2013). } \\
\text { Usability }\end{array}$ & $\begin{array}{l}\text { Usability measures the level at which a product can be used to } \\
\text { satisfy user goals effectively, efficiently and resulting in user } \\
\text { satisfaction in a specified context of use. According to Isabirye } \\
\text { (2016), the context of use relates to the users and their } \\
\text { environment that limits their capability to efficiently work or } \\
\text { make use of a technology. }\end{array}$ \\
\hline
\end{tabular}


TABLE 2: Themes and associated sample quotes.

\begin{tabular}{ll}
\hline Theme & Theme \\
\hline Functionality & $\begin{array}{l}\text { - I am convinced with the functionality on the application, the } \\
\text { application can be very useful for my condition's management } \\
\text { - Enough functionalities are what one seeks in a health } \\
\text { application for diabetes management }\end{array}$ \\
$\begin{array}{ll}\text { Information } & \text { I think the information is correct, but I must consult my doctor } \\
\text { accuracy } & \text { to verify it }\end{array}$ \\
$\begin{array}{ll}\text { Reliability } & \text { This application has helped my husband be more responsible } \\
& \text { about tracking his glucose readings and the insulin he needs } \\
& \text { to take; I can recommend it }\end{array}$ \\
$\begin{array}{ll}\text { Now you must pay for some of the most important stuff; } \\
\text { it is a ploy to make us subscribe for it }\end{array}$ \\
Usability & $\begin{array}{l}\text { It has too many ads and that is so irritating and makes it } \\
\text { difficult to use }\end{array}$ \\
\hline
\end{tabular}

reliability and security mechanisms are important towards influencing perceptions of trust in diabetes applications for self-management outcomes. Below each theme is discussed in detail.

\section{Usability}

Usability measures the level at which a product can be used to satisfy a user's goals effectively, with efficiency and resulting in user satisfaction in a specified context of use (Adikari, Mcdonald \& Campbell 2010). Within the context of a technology, the use relates to the users and their environment that limits their capability to efficiently work with or make use of a technology (Isabirye 2016). Isabirye (2016) states that in order for a technology to add value to users, it has to satisfy their needs with minimal resource use. The resources consumed may be in the form of time spent to learn or perform a function, user effort exerted or the monetary cost associated with the technology use. For mobile applications for diabetes management, usability measures ease of use by users and convenience in interacting with the mobile applications to meet their health objectives. According to Thitichaimongkhol and Senivongse (2016), usability is an after effect of features of quality affecting user experience. A decent user experience is one where the client accomplishes his or her objectives, is very happy with the procedures, encourages re-use and recommends the app to others. In the Technology Acceptance Model (TAM) (Davis 1989), it is contended that if clients perceive an application to be too difficult to utilise, they are probably going to choose other options or alternatives. The effort to utilise an application ought not to exceed the potential advantages to be achieved from its utilisation (Davis 1989). In terms of trust, the usability viewpoint has progressively been perceived as a critical quality measurement to determine the success of mobile applications.

\section{Functionality}

In IT artefacts, the functionality aspect is considered a significant contributor towards influence on user trust (Lankton \& Mcknight 2011). According to Mcknight et al. (2011), user expectations of whether a technology has the capability to complete a required task as required or not are an important contributory factor towards influencing postadoption decisions of that IT. The authors Mcknight et al. (2011) add that a technology user needs to have a positive belief that the IT system has the capability and possesses the functions and features to perform as expected if it is to be trusted. Furthermore, it is alleged that for users to be convinced the technology has the needed functionality; it is important to influence their perceived usefulness of that technology (Thatcher et al. 2011).

Fieldwork results confirm that people living with diabetes look for sufficient functionality of applications for selfmanagement of their conditions. The results further affirm that the ability of the diabetes management application in delivering the desired services, such as giving visual treatment progress and reminding patients when to take medication can make it appealing and trustworthy for patients. Lacking sufficient functionalities can lead to users having to abandon applications and refer to other methods such as reading from books about diabetes management or having to rely on doctors' advice more often as they have done before. The outcome of the study proves that functionality is an important element of trust when choosing mobile applications for management of diabetes. Therefore, this justifies the attribute of functionality in the proposed model to influence trust in applications for personal management by people living with diabetes.

\section{Information accuracy}

Information accuracy is crucial towards self-management of diabetes treatment. During the intervention, candidates were all convinced about the accuracy of the various functions of the sampled application. A patient had this to say:

'It helps me keep good record of my condition, 30 days since I have used the application, I don't think I will want a notebook to keep track of information. The application will allow easy communication of my progress. I loved the information I showed him on my last follow-up visit. Participants were clear on their decision regarding whether the information given was true or not. All participants said if the application would give wrong information from their input, they would abandon it. Users gave responses such as: "If it gives inaccurate information, then it's not serving its purpose. I will discontinue using it immediately"; "Inaccurate information could mean mismanagement of my diabetes"; and "Inaccurate information may be hazardous to health and could worsen my sickness". People living with diabetes fear being misled and putting their health at risk considering their strict medication and diet. Particularly, some patients said they would prefer to only use the reminder function as they could not tell whether the information given by other functions of the health application was accurate or reliable, unless their healthcare giver confirms it.' (Participant $2 \& 3$, male high school students aged between 14 and 19 years studying at a school in Mdantsane, East London)

'Participants were asked to input data such as results from any medical tests taken and any additional information received from their doctors. From the data the application generates progress graphs, charts and reports, which helped inform users on lifestyle changes as well as medication regimens. Based on this and other information from the application, participants were asked whether they could depend on and obey the recommendations provided by the application. Participants agreed that the diabetes application can be depended upon to follow up on medication trends to achieve health objectives. 
Other participants were happy that the application was accessible anytime and needed no data or Internet network to access it when they needed to use it. Most participants said they trusted the recommendations and would follow them without any doubts.' (Participant 1, a female student at a university, aged between 23 to 27 years)

'However, despite the views, participants still chose to consult their doctors before they could change their dietary habits during the intervention period. The consulted physicians were of the view that the diabetes management application cannot entirely replace visiting health personnel before introducing any changes to their conditions' management. Not all patients can correctly read information from the graphs and charts from the application and that's where the doctor comes in.' (Participant 4 , a retired nurse, aged above 60 years based in the rural location surrounding East London)

\section{Reliability}

Reliability entails that the system will provide continued correct service to satisfy user objectives (Avizienis et al. 2004). According to Fogg and Tseng (1999), trust is an outcome of positive belief and dependability as well as confidence in an individual process or object. In the study it was found that even when the technological and support structures are in place for diabetes patients to use on mobile platforms to assist them, users are concerned about the reliability of these platforms. Participants still raised the point of having to consult with their doctors to confirm the recommendations before obeying them. An important point was raised by almost everybody that using an app could not entirely replace their traditional methods of management such as regularly visiting local healthcare centres for consultations. Others only approved a limited number of functions on the app alleging that they could not depend on the results given.

Reliability of mobile health applications is important in that it influences other elements such as performance, usability and fault prediction in mobile applications (Meskini, Nassif \& Capretz 2013). Reliability, especially in the long run, is about whether the app will continue to work as expected and with little or no errors or problems. In this study, it was found that most applications for health purposes are developed with very limited input from professional medical staff; this raised critical trust issues about the perceived reliability of these applications by patients (Boulos et al. 2011).

The ability of the mobile application to back up data stored was found to be an important feature for participants, citing reasons such as being able to proceed on another device in the event of losing the old one or it running out of power. Responses suggested that there was a relationship between information accuracy and reliability. The application users noted that they would first seek their health providers' viewpoint before taking the suggestions from the app, regardless of the app utilising their stored history in defining the suggestions. The finding therefore suggests the need for mobile applications for diabetes self-management to demonstrate reliability, now and in future for patients to develop trust.
Similar to interpersonal trust, technology trust is generated by observing specific factors or characteristics of the trustee (Mcknight 2005). Findings from literature reviewed and the results of the empirical analysis indicate that when people living with diabetes experience mobile applications, factors of functionality, usability (easy to learn and use) and reliability mechanisms are important towards influencing perceptions of trust in diabetes applications for selfmanagement outcomes. Therefore, studying user acceptance of health will need the understanding of how user beliefs about health applications influence the beliefs towards adoption behaviour. People living with diabetes are used to getting advice from healthcare providers on managing their health conditions. With the introduction of health applications, there is the expectation that these need to perform in the same way as medical staff at health centres. While using health applications, patients may be happy to be reminded of when to take medication based on previous advice from health personnel. However, patients worry about information generated that may require them to adjust their treatment routines or which medication to take (Suh \& Han 2002). The feelings of uncertainty give rise to distrust in health applications. These concerns minimise user trust in applications for diabetes conditions management and are major obstacles towards adoption of these applications. The perceived ease of use and usefulness in the original TAM may not address these aspects sufficiently to justify adoption of health applications by diabetes patients.

Kaasinen (2005) found that user expectations in mobile applications should be in balance with the actual trustworthiness of the solutions, composed of the technical reliability, accuracy of information generated, privacy protection and the possibilities for users to keep the service under control. Findings from the empirical analysis revealed that the participants engaged had indicated their interest in using mobile applications to assist in managing their conditions. However, the results revealed that not all participants were willing to explore more features of the tried app as they lacked trust in the accuracy of recommendations and information generated. The same view was shared by researchers such as Brown, Poole and Rodgers (2004), who contended that patients were likely not to explore the features of mobile applications if they perceived the applications as risky and possessing uncertainty elements, which could affect the postadoption behaviour of using the app to manage their diabetes conditions. Furthermore, patients could be unwilling to explore a diabetes management application's full features because they fear that it may not perform reliably.

\section{Conclusion}

This article investigated components of trust in mobile applications for diabetes self-management. The components are an outcome of the findings from both the fieldwork and literature reviewed in the study. As presented in the study, key attributes of perceived trustworthiness in mobile 
applications include sufficient functionality and ensure the security of information and provision of accurate information to users. The findings further identify that ease of use, affording satisfactory user control and responsiveness to the needs of people living with diabetes in these applications are also important if applications are to generate trust from people living with diabetes and influence widespread adoption and continued use. With trust in diabetes applications, patients are convinced enough to explore more features contained in a mobile application towards meeting self-management objectives of diabetes.

\section{Acknowledgements}

This work is based on the research supported in part by the National Research Foundation of South Africa for the grant: Unique Grant No. 106954.

\section{Competing interests}

The authors declare that they have no financial or personal relationships that may have inappropriately influenced them in writing this article.

\section{Authors' contributions}

G.F.M. is the main author, while N.I. and L.C. were the research supervisors.

\section{Funding information}

This research project was jointly funded by the South African Medical Research Council (SAMRC) and Forte, the Swedish Research Council for Welfare, Working Life and Welfare.

\section{Data availability statement}

Data sharing is not applicable to this article.

\section{Disclaimer}

This article is an output from Ganizani Fidelis Mainoti's Master's research. The views expressed in this article are the authors' own and not an official position of the institution or funder.

\section{References}

Adikari, S., Mcdonald, C. \& Campbell, J., 2010, 'User experience in HMI: An enhanced assessment model', in 5th International Conference on Information and Automation for Sustainability (ICIAFs): Sustainable development through effective man-machine co-existence, Colombo, Sri Lanka, December 17-19, 2010, pp. 304-310.

Årsand, E., Frøisland, D.H., Skrøvseth, S.O., Chomutare, T., Tatara, N., Hartvigsen, G. et al., 2012, 'Mobile health applications to assist patients with diabetes: Lessons learned and design implications', Journal of Diabetes Science and Technology 6(5), 1197-1206. https://doi.org/10.1177/193229681200600525

Avizienis, A., Laprie, J., Randell, B. \& Landwehr, C., 2004, 'Basic concepts and taxonomy of dependable and secure computing', IEEE Transactions on Dependable and Secure Computing 1(1), 1-23. https://doi.org/10.1109/TDSC.2004.2

Boulos, M.N.K., Wheeler, S., Tavares, C. \& Jones, R., 2011, 'How smartphones are changing the face of mobile and participatory healthcare: An overview, with example from eCAALYX', Biomedical Engineering Online 10, 24. https://doi. org/10.1186/1475-925X-10-24
Brown, H.G., Poole, M.S. \& Rodgers, T.L., 2004, 'Interpersonal traits, complementarity, and trust in virtual collaboration', Journal of Management Information Systems 20, 115-137. https://doi.org/10.1080/07421222.2004.11045785

Brown, M.T. \& Bussell, J.K., 2011, 'Medication adherence: WHO cares?', Mayo Clinic Proceedings 86(4), 304-314. https://doi.org/10.4065/mcp.2010.0575

Davis, F.D., 1989, 'Perceived usefulness, perceived ease of use, and user acceptance', MIS Quarterly 13(3), 319-339. https://doi.org/10.2307/249008

Dayer, L., Heldenbrand, S., Anderson, P., Gubbins, P.O. \& Martin, B.C., 2013, 'Smartphone medication adherence apps: Potential benefits to patients and providers', Journal of the American Pharmacists Association 53(2), 172-181. https://doi.org/10.1331/JAPhA.2013.12202

Dube, L., Van den Broucke, S., Dhoore, W., Kalweit, K. \& Housiaux, M., 2015 'An audit of diabetes self-management education programs in South Africa', Journal of

Fogg, B.J. \& Tseng, H., 1999, 'The elements of computer credibility', in Proceedings of the SIGCHI Conference on Human Factors in Computing Systems the CHI Is the Limit - CHI'99, Pittsburgh, PA, May 15-20, 1999, pp. 80-87.

Goyal, S. \& Cafazzo, J.A., 2013, 'Mobile phone health apps for diabetes management: Current evidence and future developments', QJM 106(12), 1067-1069. https:// doi.org/10.1093/qjmed/hct203

Goyal, S., Morita, P., Lewis, G.F., Yu, C., Seto, E. \& Cafazzo, J.A., 2015, 'The systematic design of a behavioural mobile health application for the self-management of type 2 diabetes', Canadian Journal of Diabetes 40(1), 1-10. https://doi.org/10.1016/j. jcjd.2015.06.007

Hamine, S., Gerth-Guyette, E., Faulx, D., Green, B.B. \& Ginsburg, A.S., 2015, 'Impact of mHealth chronic disease management on treatment adherence and patient outcomes: A systematic review', Journal of Medical Internet Research 17(2), 1-20. https://doi.org/10.2196/jmir.3951

Hart, P. \& Saunders, C., 1997, 'Critical factors in the adoption and use of electronic data interchange', Organization Science 8(1), 23-42.

Huang, J. \& Nicol, D.M., 2013, 'Trust mechanisms for cloud computing', Journal of Cloud Computing: Advances, Systems and Applications 2(1), 9. https://doi. org/10.1186/2192-113X-2-9

International Diabetes Federation (IDF), 2015, IDF diabetes atlas seventh edition 2015 , viewed 19 July 2019, from www.diabetesatlas.org.

Isabirye, N., 2016, 'A framework for enhancing trust for improved participation in electronic marketplaces', PhD thesis, Nelson Mandela Metropolitan University, Port Elizabeth, South Africa.

Isabirye, N., Flowerday, S.V., Nanavati, A. \& Von Solms, R., 2015, 'Building technology trust in a rural agricultural e-marketplace: $\mathrm{A}$ user requirements perspective' Electronic Journal of Information Systems in Developing Countries 70(1), 1-20. https://doi.org/10.1002/j.1681-4835.2015.tb00504.x

Jackson, C., Bolen, S., Brancati, F., Batts-Turner, M. \& Gary, T., 2006, 'A systematic review of interactive computer-assisted technology in diabetes care. Interactive information technology in diabetes care', Journal of General Internal Medicine 21(2), 105-110. https://doi.org/10.1111/j.1525-1497.2005.00310.x

Jarvenpaa, S.L., Tractinsky, N. \& Vitale, M., 2000, 'Consumer trust in an Internet store', Journal of Information Technology Management 1, 45-71. https://doi. org/10.1023/A:1019104520776

Kaasinen, E., 2005, 'User acceptance of mobile services: Value, ease of use, trust and ease of adoption', PhD thesis, Tampere University of Technology (TUT) and eas.

Khansa, L., Davis, Z., Davis, H., Chin, A., Irvine, H., Nichols, L. et al., 2016, 'Health information technologies for patients with diabetes', Technology in Society 44 1-9. https://doi.org/10.1016/j.techsoc.2015.11.001

Komiak, S., 2010, 'The effects of perceived information quality and perceived system quality on trust and adoption of online reputation systems', in AMCIS 2010 Proceedings, Lima, Peru, August 12-15, 2010, p. 343.

Koo, C. \& Wati, Y., 2010, 'Toward an understanding of the mediating role of "trust" in mobile banking service: An empirical test of Indonesia case', Journal of Universal Computer Science 16(13), 1801-1824.

Kumar, S., Nilsen, W.J., Abernethy, A., Atienza, A., Patrick, K., Pavel, M. et al., 2013, 'Mobile health technology evaluation', American Journal of Preventive Medicine 45(2), 228-236. https://doi.org/10.1016/j.amepre.2013.03.017

Lankton, N.K. \& McKnight, D.H., 2011, 'What does it mean to trust Facebook?', ACM SIGMIS Database 42(2), 32-54. https://doi.org/10.1145/1989098.1989101

Marcano, J.S.J.S., Huckvale, K., Greenfield, G., Car, J. \& Gunn, L.H., 2013, 'Smartphone and tablet self-management apps for asthma', The Cochrane Database of Systematic Reviews 11(11), CD010013.

Mcknight, D., Carter, M., Thatcher, J. \& Clay, P., 2011, 'Trust in a specific technology: An investigation in its components and measures', ACM Transactions on Management Information Systems 2(2), 1-12. https://doi.org/10.1145/1985347. 1985353

Mcknight, D.H., 2005, 'Trust in information technology', The Blackwell encyclopaedia of management, vol. 7, Management Information Systems, pp. 329-331.

Meskini, S., Nassif, A.B. \& Capretz, L.F., 2013, 'Reliability models applied to mobile applications', in 2013 IEEE Seventh International Conference on Software Security and Reliability Companion, Gaithersburg, MD, June 18-20, 2013, pp. 155-162.

Nathan, D.M., Cleary, P.A., Backlund, J.Y., Genuth, S.M., Lachin, J.M., Orchard, T.J., et al., 2005, 'Diabetes control and complications trial/epidemiology of diabetes interventions and complications (DCCT/EDIC) Study Research Group. Intensive diabetes treatment and cardiovascular disease in patients with type 1 Intensive diabetes treatment and cardiovascular disease in patients with type 1
diabetes', The New England Journal of Medicine 353(25), 2643-2653. https://doi. diabetes', The New England Jour
org/10.1056/NEJMoa052187 
Nyoni, T. \& Piderit, R., 2012, 'Enhancing trust in cloud computing', in 14th Annual Conference on World Wide Web Applications, Durban, South Africa, November 7-9, 2012, pp. 1-16.

Perera, A.I., Thomas, M.G., Moore, J.O., Faasse, K. \& Petrie, K.J., 2014, 'Effect of a smartphone application incorporating personalized health-related imagery on adherence to antiretroviral therapy: A randomized clinical trial', AIDS Patient Care and STDs 28(11), 579-586. https://doi.org/10.1089/apc.2014.0156

Pyster, A., Olwell, D.H., Hutchison, N., Enck, S., Anthony, J.F. Jr., Henry, D. et al., (Eds.), 2013, 'Reliability, availability, and maintainability', in Guide to the Systems Engineering Body of Knowledge (SEBOK), pp. 851-865, The Trustees of the Stevens Institute of Technology, Hoboken, NJ.

Schnall, R., Higgins, T., Brown, W., Carballo-Dieguez, A. \& Bakken, S., 2015, 'Trust, perceived risk, perceived ease of use and perceived usefulness as factors related to mHealth technology use', Studies in Health Technology and Informatics 216 467-471.
Soderstrom, E., 2009, 'Security, assurance and privacy: Organizational challenges', in D. Gurpreet (ed.), Proceedings of the 8th Annual Security Conference Discourses in Security Assurance, Assurance and Privacy, April 15-16, pp. 1-14, Las Vegas, NV.

Suh, B. \& Han, I., 2002, 'Effect of trust on customer acceptance of Internet banking', Electronic Commerce Research and Applications 1, 247-263. https://doi. org/10.1016/S1567-4223(02)00017-0

Thatcher, J.B., McKnight, D.H., Baker, E.W., Arsal, R.E. \& Roberts, N.H., 2011, 'The role of trust in postadoption IT exploration: An empirical examination of knowledge management systems', IEEE Transactions on Engineering Management 58(1), 56-70. https://doi.org/10.1109/TEM.2009.2028320

Thitichaimongkhol, K. \& Senivongse, T., 2016, 'Enhancing usability heuristics for android applications on mobile devices', in Proceedings of the World Congress on Engineering and Computer Science, I.

Wicks, P. \& Chiauzzi, E., 2015, "'Trust but verify" - Five approaches to ensure safe medical apps', BMC Medicine 13(1), 205. https://doi.org/10.1186/s12916-015-0451-z 